\title{
Estimação de parâmetros genéticos de ovinos da raça Santa Inês utilizando modelos uni e bicaracterística
}

\section{Estimation of genetic parameters Santa Inês Sheep breed using single and two - traits models}

\author{
Geane Conceição Carvalho ${ }^{\mathrm{I}}$ Leandro Teixeira Barbosa $^{\mathrm{II}}$ Tatiana Maia de Oliveira $^{\mathrm{I}}$ \\ Fernanda Érica Pereira FonsecaII Evandro Neves Muniz ${ }^{\text {IV }}$ \\ Hymerson Costa Azevedo ${ }^{\text {IV }}$
}

RESUMO

Objetivou-se nesse trabalho, estimar os parâmetros genéticos para características de crescimento em ovinos da raça Santa Inês através do Método da Máxima Verossimilhança Restrita (REML). Os componentes de (co)variâncias e os parâmetros genéticos foram estimados pelo Software MTDFREML (Multiple Trait Derivative-Free Restricted Maximum Likelihood). As características avaliadas em modelos uni e bicaracterística foram: peso ao nascimento (PN) e peso ao desmame (P90). Além dos efeitos fixos de sexo, grupo contemporâneo e tipo de parto, foram utilizados os seguintes efeitos aleatórios: efeito genético aditivo direto, efeito genético aditivo materno e efeito residual. As estimativas de herdabilidade aditiva direta para PN foram 0,20 e 0,21 , para os modelos uni e bicaracterística, respectivamente. As estimativas de herdabilidade aditiva direta para $P 90$ foram 0,04 e 0,07, para os modelos uni e bicaracterística, respectivamente. A correlação genética entre PN e P90 foi de 0,11, indicando que ambas as características devem ser trabalhadas simultaneamente.

Palavras-chave: correlação genética, efeito materno, herdabilidade, modelo animal, ovinos deslanados.

\section{ABSTRACT}

The objective of this study is to estimate genetic parameters for growth traits in sheep Santa Ines breed by Restricted Maximum Likelihood (REML). The (co)variance components and genetic parameters were estimated by MTDFREML Software (Multiple Trait Derivative-Free Restricted Maximum Likelihood). The characteristics evaluated in single and two-trait models were: birth weight $(B W)$ and weaning weight $(W W)$. In addition to the fixed effects of sex, contemporary group and parity type, we used the following random effects: direct genetic effect, maternal additive genetic and residual effects. The direct additive heritability estimates for $B W$ were 0.20 and 0.21 for single and two-trait models, respectively. Heritability estimates for direct additive $\mathrm{WW}$ were 0.04 and 0.07 for single and two-trait models, respectively. The genetic correlation between $B W$ and $W W$ was 0.11 , indicating that both traits should be worked on simultaneously.

Key words: genetic correlation, maternal effect, heritability, animal model, hair sheep.

\section{INTRODUÇÃO}

No Brasil e no mundo, cresce a demanda por carnes ovinas como também a necessidade de melhorar a qualidade genética de seus rebanhos. O melhoramento genético tem papel importante neste processo, por ser um dos principais instrumentos para identificação de animais superiores (SARMENTO et al., 2006).

A identificação de animais superiores e a posterior seleção dependem de vários fatores, dentre eles, a disponibilidade de estimativas de parâmetros genéticos acurados para as características de interesse. A acurácia da estimativa desses parâmetros depende de um conjunto de fatores, entre eles, o número de informações utilizadas, o modelo estatístico e o método de estimação dos parâmetros genéticos (BARBOSA et al., 2006).

Estimativas de parâmetros genéticos para características de crescimento em ovinos de corte são pouco encontradas na literatura (VAN WYK et al.

\footnotetext{
'Programa de Pós-graduação em Biotecnologia de Recursos Naturais, Universidade Federal de Sergipe (UFS), São Cristovão, SE, Brasil. IIDepartamento de Zootecnia, UFS, Av. Marechal Rondon, s/n Bairro Rosa Elze, 49100-000, São Cristovão, SE, Brasil. E-mail: leandro@ufs.br. Autor para correspondência.

IIIDepartamento de Medicina Veterinária, UFS, São Cristovão, SE, Brasil.

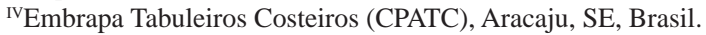


1993; MARIA et al. 1993; TOSH \& KEMP, 1994). Quando se refere a estimativas separando os efeitos genéticos aditivos direto e materno, elas ocorrem ainda em menor número.

As principais informações para avaliação genética e seleção de ovinos de corte são os pesos corporais mensurados durante o período de crescimento até a desmama onde depende de efeitos genéticos diretos ou capacidade de crescimento do jovem e de efeitos genéticos maternos também dito valor leiteiro da mãe ou aptidão ao aleitamento. Estes parâmetros permitem supor uma seleção eficaz em ovinos para corte, uma vez que apresentam elevada herdabilidade.

Os pesos em determinadas idades apresentam características diferentes, geralmente correlacionadas, o que torna fundamental conhecer a magnitude e a direção de tais correlações, uma vez que a seleção de uma delas poderá promover mudanças nas demais (SARMENTO et al., 2006). Segundo esse mesmo autor, a decisão por modelos multicaracterísticas, que leva em consideração duas ou mais característica, em substituição ao unicaracterística, irá depender, principalmente, das herdabilidades e correlações entre as características, pois conforme a combinação entre tais parâmetros, a eficiência entre esses dois modelos pode ser semelhante. Entretanto, independente do aumento de eficiência, poderá haver outras razões para escolha do modelo multicaracterísticas, como a remoção do viés causado pela seleção sequencial.

Contudo, a avaliação por meio de modelos multicaracterística pode ocasionar dificuldade de convergência, principalmente em modelos mais complexos.

Objetivou-se nesse trabalho, estimar os parâmetros genéticos para características de crescimento em ovinos da Raça Santa Inês, através do Método da Máxima Verossimilhança Restrita (REML) por meio de modelos uni e bicaracterística.

\section{MATERIAL E MÉTODOS}

Para realização deste estudo foram utilizados 4019 animais da raça de Santa Inês, nascidas no período de 1998 a 2008, sendo 3.036 registros para peso ao nascer e 2.111 para peso a desmama. Os animais avaliados são provenientes de um rebanho experimental pertencente à Empresa Brasileira de Pesquisa Agropecuária (EMBRAPA TABULEIROS COSTEIROS), localizado no município de Frei Paulo, Estado de Sergipe, região Nordeste do Brasil, situada a uma latitude de $10,5^{\circ}$ sul e longitude de $37,5^{\circ}$ oeste, com precipitação pluviométrica anual média de $1100 \mathrm{~mm}$ e temperatura média de $25,4^{\circ} \mathrm{C}$. As práticas de manejo dos rebanhos foram constantes durante todo o período e os rebanhos permaneceram em campos de pastagem nativa e nativa melhorada durante a maior parte do ano.

Neste trabalho foram estudadas as características de crescimento: peso ao nascer e peso a desmama ajustado para 90 dias utilizando-se a expressão abaixo:

$P x i=[(P y i-P N) x i] / y i+P N$,

Onde:

$P x i=$ peso estimado para a idade $x i$, sendo $x i=90$;

dias de idade;

$P y i=$ peso tomado à idade mais próxima de xi;

$Y i$ = idade em dias, mais próxima de xi; e

$P N=$ peso ao nascimento;

Para a avaliação dos paramentos genéticos foram utilizados à teoria dos modelos mistos e como efeitos fixos, foram utilizados: sexo, tipo de parto (com informações de animais nascidos de parto simples, duplo triplo e quádruplo) e grupo de contemporâneo, formados pela combinação do ano com estação de nascimento nos períodos de janeiro a março, abril a junho, julho a setembro e outubro a dezembro; foram incluídos também os seguintes efeitos aleatórios: efeito genético aditivo direto, efeito genético materno e efeito residual. O efeito de ambiente permanente materno não foi considerado neste estudo, pois em análises preliminares, verificou-se que, ao incluir esse efeito, a convergência no processo iterativo foi dificultada. Os componentes de (co)variâncias e os parâmetros genéticos foram estimados pelo Software MTDFREML (Multiple Trait Derivative-Free Restricted Maximum Likelihood), desenvolvido por BOLDMAN et al. (1995) através da metodologia de Máxima Verossimilhança Restrita (REML), por meio de um algoritmo não-derivativo (GRASER et al., 1987), empregando modelos animais em análises uni e bicaracterísticas, em que a covariância entre os efeitos direto e materno não foi assumido com zero. Cada análise foi reiniciada com diferentes valores iniciais, para garantir que os valores dos componentes estimados correspondessem ao máximo absoluto da função de verossimilhança, na tentativa de evitar a convergência para um máximo local. O critério de convergência foi considerado quando a variância do "Simplex" foi inferior a $10^{-9}$. O modelo utilizado foi como se segue:

Ciência Rural, v.44, n.1, jan, 2014. 
$y=X b+Z_{1} d+Z_{2} m+e ;$

em que:

$y=$ vetor de observações;

$b$ = vetor de efeitos fixos de grupo contemporâneo;

$X=$ matriz de incidência de efeitos fixos de grupo contemporâneo;

$\boldsymbol{d}$ = vetor de efeitos genéticos aditivos diretos;

$Z_{1}=$ matriz de incidência de efeitos genéticos aditivos diretos;

$m$ = vetor de efeitos genéticos aditivos maternos;

$Z_{2}=$ matriz de incidência de efeitos genéticos aditivos maternos;

$e=$ vetor de efeito residual.

\section{RESULTADOS E DISCUSSÕES}

O peso médio ao nascer 3,58 $\pm 0,78 \mathrm{~kg}$ encontrado neste estudo (Tabela 1) mostrou-se similar aos valores encontrados por outras pesquisas para a raça Santa Inês. SOUSA et al. (1999) encontraram o mesmo valor (3,58 kg), SILVA et al. (1995) e SARMENTO et al. (2006) obtiveram médias de 3,49 $\mathrm{kg}$ e 3,61 kg respectivamente. Entretanto nossos resultados apresenta-se superior aos 3,28 $\mathrm{kg}$ encontrados por MACHADO et al. (1999) evidenciando a superioridade no desenvolvimento dos participantes deste estudo.

O valor médio registrado para peso a desmama foi de $17,81 \pm 4,70 \mathrm{Kg}$, esse resultado apresentou-se próximo ao reportado por QUESADA et al. (2002) para mesma raça, no entanto com um número inferior de observações.

As estimativas de herdabilidade direta obtidas para PN na análise unicaracterística foram de magnitude moderada 0,20 (Tabela 2), indicando uma boa resposta à seleção direta para todas as características, corroborando com as encontradas por SARMENTO et al. (2006), que também observaram valores para PN de 0,20 na análise unicaracterística. Sendo assim pode haver ganho genético, mediante seleção. Resultados semelhantes ao do presente estudo foram encontrados por MCMANUS \& MIRANDA(1998), com animais da raça Bergamácia onde obtiveram herdabilidade média de $(0,22)$, para PN. Porém a herdabilidade observada neste estudo mostrou-se superior aos reportados por SOUSA (2004), que obteve herdabilidade direta para as características peso ao nascer em ovinos da raça Santa Inês de 0,15, maior também que as encontradas por SOUSA et al. (1999), que obteve estimativas de herdabilidade direta de baixa magnitude variando de
0,11 a 0,16 , indicando pequena resposta à seleção direta para todas as características que eles avaliaram.

As estimativas de covariância entre o efeito direto e materno para peso ao nascer foi negativa e próxima de zero $(-0,01)$. Este resultado está próximo do obtido por VAN WYK et al. (1993), que relataram, estimativa de $-0,05$, porém está muito distante da obtida por MARIA et al. (1993), que obtiveram estimativas negativas e próximas da unidade.

A estimativa de herdabilidade para o efeito genético materno foi de $(0,41)$. Mesmo o efeito genético materno permanecendo evidente até a desmama, verificou-se tendência de declínio, concordando com a maioria dos resultados encontrados na literatura (SOUSA et al., 1999; QUESADA et al., 2002). Essa tendência era de certa forma, esperada, pelo fato do cordeiro tornar-se menos dependente da mãe à medida que cresce.

No presente trabalho as correlações entre os efeitos aditivo direto e materno para PN foi negativo $(-0,83)$, maiores que as observadas por

Tabela 1 - Número de observações e algumas estatísticas descritivas para as características peso ao nascer (PN) e peso a desmama (P90).

\begin{tabular}{|c|c|c|}
\hline Parâmetro & $\mathrm{PN}$ & P90 \\
\hline $\mathrm{N}^{\circ}$ de observações & 3036 & 2111 \\
\hline Média & 3,58 & 21,68 \\
\hline Desvio-padrão & 0,78 & 4,70 \\
\hline $\mathrm{CV} \%$ & 21,68 & 26,41 \\
\hline \multicolumn{3}{|c|}{ Estação de nascimento } \\
\hline jan-mar & 139 & 123 \\
\hline abr-jun & 965 & 539 \\
\hline jul-set & 1744 & 1289 \\
\hline out-dez & 188 & 160 \\
\hline \multicolumn{3}{|l|}{ Ano de nascimento } \\
\hline 1998 & 278 & 256 \\
\hline 1999 & 398 & 328 \\
\hline 2000 & 503 & 395 \\
\hline 2003 & 199 & \\
\hline 2004 & 338 & \\
\hline 2005 & 475 & 405 \\
\hline 2006 & 308 & 257 \\
\hline 2007 & 311 & 269 \\
\hline 2008 & 226 & 201 \\
\hline \multicolumn{3}{|l|}{ Sexo da cria } \\
\hline macho & 1491 & 1003 \\
\hline fêmea & 1545 & 1108 \\
\hline \multicolumn{3}{|l|}{ Tipo de nascimento } \\
\hline simples & 1425 & 1033 \\
\hline duplo & 1449 & 1006 \\
\hline triplo & 129 & 55 \\
\hline quádrupo & 33 & 17 \\
\hline
\end{tabular}


SARMENTO et al. (2006), e SOUSA et al. (1999) que observaram correlações genéticas para $\mathrm{PN}$ de $-0,47$ e $-0,15$ respectivamente.

A herdabilidade direta encontrada no presente estudo para P90 foi de 0,04, corroborando com as observadas por SOUSA et al. (1999), para a idade de 112 dias (idade a desmama).

Estimativa de covariância entre o efeito direto e materno foi negativa e abaixo de zero $(-1,32)$ para P90. Estes resultados estão distantes das obtidas por MARIA et al. (1993), que obtiveram estimativas negativas e próximas da unidade.

A estimativa de herdabilidade materna para P90 foi moderada 0,20, mostrando superior as relatadas por SOUSA et al. (1999) que obtiveram valores de 0,10 . Valores semelhantes ao do presente estudo foram estimados por MARIA et al. (1993). Já TOSH \& KEMP (1994) encontraram valores de herdabilidade materna de 0,16, 0,21 e 0,05 para peso aos 50 dias de idade, respectivamente para ovinos das raças Hampshire Down, Poll Dorset e Romanov.

As correlações entre os efeitos aditivo direto e materno para peso a desmama $(-0,87)$, foram negativas, semelhantes às observadas por SARMENTO et al. (2006). Porém SOUSA et al. (1999) observaram correlação genética baixa e positiva $(0,31)$ entre os efeitos direto e materno para peso aos 112 dias (desmame). De acordo com SARMENTO et al. (2006), correlação genética para peso pós-desmame mostra uma tendência positiva de média a alta magnitude, mas não igual à unidade, pois pode ser reflexo do número de informações dos dados. Muitas discussões têm sido feitas sobre o sinal da correlação entre os efeitos direto e materno. Segundo SARMENTO et al. (2006), em ovinos os resultados encontrados são de certo modo contraditórios. Causas dessas correlações negativas têm sido apontadas na literatura como possível covariância ambiental negativa entre mãe e filho, que não é considerado na análise (SWALWE, 1993). ROBINSON (1996) considera que as estimativas negativas são, provavelmente, consequência de variação adicional entre reprodutores ou da variação da interação reprodutor $\mathrm{x}$ ano, do que um relacionamento genético negativo verdadeiro.

As estimativas de variância genética aditiva na análise bicaracterística foram similares para peso ao nascer e superiores para peso a desmama em relação às estimadas em análise unicaracterística. Ressalva-se que a análise bivariada envolvendo duas características permite explorar com precisão estimativa de parâmetros genéticos e acurácia das avaliações quando comparadas à análise unicaracterística, devido à contribuição dos genes que atuam em conjunto sob duas características, o que auxilia na estimação dos parâmetros genéticos da característica objeto de seleção (PEREIRA, 2004).

Neste estudo, observamos um pequeno aumento na estimativa de herdabilidade para PN e P90, quando comparadas às obtidas pelo modelo unicaracterísticas, corroborando com SOUSA et al. (1999) que também observou aumento nas estimativas de herdabilidade para peso ao nascer e peso a desmame no modelo bicaracterísticas quando comparado ao modelo unicaracterísticas. Observou superioridade quando considerado a estimação em análise bicaracterística, podendo ser justificado pela possível existência de genes atuantes no peso ao desmame que contribui significamente para o acréscimo dos parâmetros genéticos na característica.

As estimativas de herdabilidade direta para peso a desmama no modelo bicaracterística foram um pouco superior às obtidas no modelo unicaracterística, (Tabela 2) esses resultados sugerem que a informação de outra característica contribuiu na estimação das variâncias entre os efeitos genéticos aditivos diretos e, de certa forma melhorando os efeitos genéticos direto e materno. As estimativas de herdabilidade materna apresentaram o mesmo comportamento das obtidas pelos modelos unicaracterística, porém com valores ligeiramente superiores.

A estimativa de correlação entre o efeito direto e materno para PN e P90 foi o mesmo encontrado nas análises unicaracterísticas (-0,83 e -0,87) respectivamente. Estes resultados estão próximos dos obtidos por MARIA et al. (1993), que obtiveram estimativas negativas e próximas da unidade.

Neste estudo, a estimativa de correlação genética aditiva direta entre PN e P90 foi de 0,11, o que sugere associação baixa entre essas duas características. Isso significa que deve ser realizada seleção simultânea para ambas as características.

\section{CONCLUSÃO}

O progresso do melhoramento genético de ovinos da raça Santa Inês visando à produção de carne, deve levar em consideração a avaliação simultânea de peso ao nascer e peso ao desmame, que são importantes características de crescimento.

$\mathrm{O}$ efeito genético materno no modelo apresentou importante influência sobre as características estudadas, devendo, portanto ser considerado nos estudos de características de crescimento. 
Tabela 2 - Estimativas do componente de (co)variância e de parâmetros genéticos para as características peso ao nascer (PN) e peso a desmama (P90) em análise unicaracterítica e bicaracterística

\begin{tabular}{|c|c|c|c|c|}
\hline \multirow[b]{2}{*}{ Parâmetros } & \multicolumn{2}{|c|}{ 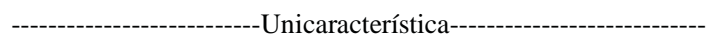 } & \multicolumn{2}{|c|}{ 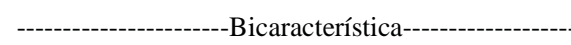 } \\
\hline & $\mathrm{PN}$ & P90 & $\mathrm{PN}$ & $\mathrm{P} 90$ \\
\hline$\sigma_{d}^{2}$ & 0,07 & 0,46 & 0,07 & 0,79 \\
\hline$\sigma_{e}^{2}$ & 0,19 & 8,05 & 0,19 & 8,05 \\
\hline$\sigma_{p}^{2}$ & 0,36 & 10,94 & 0,36 & 11,00 \\
\hline$\sigma_{d m}$ & $-0,08$ & $-1,32$ & $-0,08$ & $-1,32$ \\
\hline$\sigma_{m}^{2}$ & 0,17 & 2,18 & 0,13 & 2,95 \\
\hline$h_{d}^{2}$ & $0,20 \pm 0,03$ & $0,04 \pm 0,05$ & $0,21 \pm 0,05$ & $0,07 \pm 0,06$ \\
\hline$h_{m}^{2}$ & $0,41 \pm 0,06$ & $0,20 \pm 0,07$ & $0,37 \pm 0,07$ & $0,27 \pm 0,07$ \\
\hline$r_{d m}$ & $-0,83 \pm 0,35$ & $-0,87 \pm 0,47$ & $-0,83 \pm 0,45$ & $-0,87 \pm 0,61$ \\
\hline
\end{tabular}

$\sigma_{d}^{2}=$ variância genética aditiva direta; $\sigma_{e}^{2}=$ variância residual; $\sigma_{p}^{2}=$ variância fenotípica $\sigma_{d m}=$ co-variância genética aditiva direta e materna; $\sigma_{m}^{2}=$ variância genética aditiva materna; $h_{d}^{2}=$ herdabilidade genética aditiva direta; $h_{m}^{2}=$ herdabilidade genética aditiva materna; $r_{d m}=$ correlação entre efeito genético aditivo direto e efeito materno.

As análises bicaracterísticas, por utilizarem maior número de informações e as relações entre as características, possibilitaram resgatar parte da variância aditiva direta, levando a estimativas maiores de herdabilidade.

\section{AGRADECIMENTOS} dos dados

A Embrapa Tabuleiros Costeiros pela disponibilidade

\section{REFERÊNCIAS}

BARBOSA, L. et al. Avaliação de características de qualidade da carne de suínos por meio de componentes principais. Revista Brasileira de Zootecnia, v.35, n.4, p.1639-1645, 2006. Disponível em: <http://www.scielo.br/pdf/rbz/v35n4s0/ a09v354s.pdf $>$ Acessado em: 27 ago. 2012. doi:10.1590/S151635982006000600009 .

BOLDMAN, K.G. et al. A manual for use of MTDFREML: a set of programs to obtain estimates of variances and co-variances (DRAFT). Lincoln: Department of Agriculture/Agriculture Research Service, 1995. 120p.

GRASER, H.U. et al. A derivative-free approach for estimating variance components in animal model by restricted maximum likelihood. Jounal Animal Science. v.64, p.1362-1370, 1987. Disponível em: <www.scielo.br/pdf/rbz/v35n4s0/a09v354s.pdf > Acessado em: 27 ago. 2012.
MACHADO, J.B.B. et al. Parâmetros Reprodutivos de Ovinos Deslanados Morada Nova e Santa Inês mantidos em Pastagem Cultivada, no Estado do Ceará. Revista Cientifica de Produção Animal, v.1, n2, p. 205-210, 1999. Disponivel em: <www.ojs.ufpi. br/index.php/rcpa/article/view/29/28> Acessado em: 27 ago. 2012.

MARIA, G. A. et al. Estimates of variance due to direct and maternal effects for growth traits of Romanov sheep. Journal of Animal Science, v.71, p.845-849, 1993. Disponível em: <http:// www.journalofanimalscience.org/content/71/4/845> Acessado em: 19 nov. 2012.

McMANUS, C.; MIRANDA, R.M. Estimativas de parâmetros genéticos em ovinos Bergamácia. Revista da Sociedade Brasileira de Zootecnia, v.27, n.5, p.216-221, 1998. Disponível em: <http:// www.revistasbz.org.br/scripts/revista/sbz1/Artigos/2278.pdf> Acessado em 27 ago. 2012.

PEREIRA, J. C. C. Melhoramento genético aplicado à produção animal. 4 ed. Belo Horizonte: FEPMVZ Editora. 609p. 2004.

QUESADA, M. et al. Efeitos Genéticos e Fenotípicos sobre Características de Produção e Reprodução de Ovinos Deslanados no Distrito Federal. Revista Brasileira de Zootecnia, v.31, n.1, p.342-349, 2002 (suplemento). Disponível em: <http://www. scielo.br/pdf/rbz/v31n1s0/10314.pdf> Acessado em 27 ago. 2012. doi:10.1590/S1516-35982002000200008

ROBINSON, D.L. Estimation and interpretation of direct and maternal genetic parameters for weight of Australian Angus cattle. Livestock Production Science, v.45, p.1-11, 1996. Disponível em: <http://www.sciencedirect.com/science/article/ pii/0301622695000836> Acessado em 19 nov. 2012. doi: 10.1016/0301-6226(95)00083-6. 
SARMENTO, J.L.R. et al. Estudo da curva de crescimento de ovinos Santa Inês. Revista Brasileira de Zootecnia, v.35, p.435442, 2006. Disponível em: <http://www.scielo.br/pdf/rbz/v35n2/ a14v35n2.pdf > Acessado em 27 ago. 2012. doi: 10.1590/S151635982006000200014

SILVA, F.L. et al. Efeito de ambiente e de reprodutor sobre as características de crescimento e reprodução em ovinos Santa Inês no Estado do Ceará. Revista Brasileira de Zootecnia, v.24, n.4, p.559-569, 1995.

SOUSA, W.H. et al. Estimativas de componentes de (co)variância e herdabilidade direta e materna de pesos corporais em ovinos da raça Santa Inês. Revista Brasileira de Zootecnia, v.28, p.12521262, 1999. Disponível em: <http://www.scielo.br/pdf/rbz/v28n6/ a12v28n6.pdf> Acessado em 27 ago. 2012. doi:10.1590/S151635981999000600012

SOUSA, J.E.R. Parâmetros Genéticos e Fenotípicos de Pesos do Nascimento aos 120 dias e de Ganho de Peso do Nascimento aos 90 dias de Idade em Ovinos da Raça Santa Inês. 2004. 43 p. Dissertação (Mestrado em Zootecnia) - Universidade Federal do Ceará, Fortaleza, 2004.

SWALWE, H.H. Estimation of direct and maternal (co)variance components for growth traits in Australian Simmental beef cattle. Journal of Animal Breeding and Genetics, v.110 p. 241-252, 1993. Disponivel em: <http://onlinelibrary.wiley.com/ doi/10.1111/j.1439-0388.1993.tb00736.x/abstract> Acessado em: 19 nov. 2012. doi: 10.1111/j.1439-0388.1993.tb00736.x.

TOSH, J.J.; KEMP, R.A. Estimations of variance components for lamb weights in three sheep populations. Journal of Animal Science, v.72, p.1184-1191, 1994. Disponível em: <http://www.journalofanimalscience. org/content/72/5/1184> Acessado em: 19 nov. 2012.

VAN WYK, J.B. et al. Variance components and heritability estimates of early growth traits in the Elsenburg Dormer sheep stud. South African Journal Animal Science, v.23, p.72-76. 1993. Disponível em: <http://sasas.co.za/sites/sasas.co.za/files/ van\%20WykB23Issue3.pdf> Acessado em 19 nov. 2012. 